\title{
Can Waist Circumference Be Used as an Anthropometric Parameter to Assess the Obesity Related Pregnancy Outcome: A Case Control Study
}

\author{
Anjali Gupta*, Sonika Mann, Savira Sethi \\ Department of Obstetrics and Gynaecology, Pt. B.D. Sharma PGIMS, Rohtak, India \\ Email: ajiii2003@yahoo.co.in
}

Received 25 June 2015; accepted 30 August 2015; published 2 September 2015

Copyright (C) 2015 by authors and Scientific Research Publishing Inc.

This work is licensed under the Creative Commons Attribution International License (CC BY). http://creativecommons.org/licenses/by/4.0/

(c) (i) Open Access

\begin{abstract}
Introduction: The prevalence of obesity is increasing in women of reproductive age. Maternal obesity is associated with increased morbidity and mortality for both mother and offspring. BMI has been criticized as a limited measure of total obesity. Measurement of waist circumference can be useful in the assessment of abdominal obesity and disease risk. The study is aimed to evaluate the waist circumference as an anthropometric parameter in identifying women at risk of developing obstetric complications. Material and Methods: A prospective study was conducted at a tertiary health care centre on 200 antenatal women of age between 18 to 35 years with singleton pregnancy attending the antenatal clinic before 8 weeks of gestation. Women were divided into two groups. Group I included 100 women with waist circumference $<80 \mathrm{~cm}$ and Group II included 100 women with waist circumference $\geq 80 \mathrm{~cm}$. Weight, height and waist circumference were measured and BMI was calculated. All the women were followed throughout their pregnancies as per the routine antenatal follow up. The fetomaternal outcome was recorded and analyzed statistically. Results: The two groups were comparable in age, parity and demographic profile. The maternal and neonatal complications-preeclampsia ( $p=0.0052$, RR 0.5062, 95\% CI $0.2935-0.8728)$, gestational diabetes mellitus, preterm labor, postdatism, need for induction of labor (p value 0.0081 , RR 0.6263, 95\% CI 0.4314, 0.9091), instrumental vaginal delivery, cesarean delivery $(p=0.0072$, RR 0.5745, 95\% CI 0.3696, 0.8929), shoulder dystocia, PPH, macrosomia, neonatal asphyxia, admission to NICU were reported more in Group II women as compared to Group I. Conclusion: Assessment of waist circumference in early pregnancy provides a simple and practical parameter for predicting obesity related pregnancy outcome. All pregnancies in centrally obese women (waist circumference $\geq 80 \mathrm{~cm}$ ) shall be acknowledged as high risk.
\end{abstract}

${ }^{*}$ Corresponding author.

How to cite this paper: Gupta, A., Mann, S. and Sethi, S. (2015) Can Waist Circumference Be Used as an Anthropometric Parameter to Assess the Obesity Related Pregnancy Outcome: A Case Control Study. Open Journal of Obstetrics and Gynecology, 5, 528-534. http://dx.doi.org/10.4236/ojog.2015.510076 


\section{Keywords}

\section{Waist Circumference, Obesity, Pregnancy}

\section{Introduction}

Obesity is defined by the WHO as abnormal or excessive fat accumulation that presents a risk to an individual's health [1]. India is now facing a double burden of this disease with under nutrition and underweight on one side, and a rapid upsurge in obesity and overweight, particularly in the urban settings on the other side [2]. A crude population measure of obesity is the body mass index (BMI) which is a simple index of weight-for-height—a person's weight in kilograms is divided by the square of the height in meters $\left(\mathrm{kg} / \mathrm{m}^{2}\right)$ [1]. BMI has been criticized as a limited measure of total obesity [3].

The measurement of waist circumference provides information regarding fat topography-where body fat is stored. It is an indicator of internal fat deposits, which can coat the heart, kidneys, liver and pancreas. This is important because visceral fat in particular appears to be associated with insulin resistance which leads to type 2 diabetes and is also associated with adverse lipid profiles which in turn predispose to cardiovascular disease [4].

The prevalence of obesity is also increasing in women of reproductive age and currently it is estimated that more than one in five pregnant women are obese [5]. Maternal obesity is associated with increased morbidity and mortality for both mother and offspring [6]. High pregravid body mass index (BMI) and excessive gestational weight gain are also important predictors of short-term postpartum morbidity and higher postpartum weight retention, with the latter being associated with increased risks during future pregnancies and of lifelong obesity for women [7]. Offspring of obese mothers tend to be large for gestational age at birth and are at a higher risk of late fetal death, congenital anomaly, and admission to the neonatal unit [8] [9].

For BMI, height must be measured accurately, because small errors in the denominator are exaggerated by squaring. Also, as pregnancy progresses, this index is influenced by gestational weight gain in lean tissues, thus limiting its use in pregnancy. The use of pre-pregnancy BMI as an indicator of obesity in pregnancy, may be complicated by the fact that the weight used for this calculation is frequently self-reported, producing inaccuracies [10].

Measurements of waist circumference can be useful in the assessment of abdominal obesity and disease risk. There is a limited research regarding the use of waist circumference measurements to assess obesity related risks in pregnant women.

The present study was aimed to evaluate the waist circumference as an anthropometric parameter in identifying women at risk of developing obesity related obstetric complications.

\section{Material and Methods}

The present study was a prospective clinical study comprising of 200 antenatal women of age between 18 to 35 years with singleton pregnancy attending the antenatal clinic of the Department of Obstetrics and Gynecology of tertiary health care centre, before 8 weeks of gestation. It has been passed through the institute Ethics Committee prior to the study being undertaken. Antenatal women with multiple pregnancy, any medical disorder at the time of registration, history of previous caesarean section and with BMI $<18.5 \mathrm{~kg} / \mathrm{m}^{2}$ were excluded from the study. Those who met the criteria were enrolled and were divided into two groups-Group I (control group) included 100 women with waist circumference $<80 \mathrm{~cm}$ and Group II (case group) included 100 women with waist circumference $\geq 80 \mathrm{~cm}$. The cut off value of $80 \mathrm{~cm}$ was taken based upon NICE guidelines [11].

An informed written consent was taken from all the women after explaining the type and purpose of study. They were subjected to detailed history and clinical examination. Gestational age was determined by the date of last menstrual period if she was sure of her dates and had regular menstrual cycles. Ultrasonography was done in all women to confirm the gestational age and to rule out multiple pregnancy. Waist circumference was measured in standing position, using a measuring tape after exposing the abdomen and positioning her with feet shoulder width apart and arms crossed over the chest, to the nearest of $0.5 \mathrm{~cm}$. Waist circumference was taken at the uppermost lateral border of the iliac crest at the end of gentle expiration with the tape being placed perpendicular to the long axis of the body and horizontal to the floor. Body mass index was also calculated, and for that weight 
was measured to the nearest of $0.1 \mathrm{Kg}$ with digital scales without heavy clothing and height was measured to the nearest of $0.5 \mathrm{~cm}$. Three times the waist circumference was measured and the smallest of them was taken into consideration. Women were subjected to ultrasonography for congenital anomalies at 18 to 20 weeks of gestation.

They were followed throughout their pregnancies as per the routine antenatal follow up and up to 6 weeks after delivery. At every follow up visit, blood pressure, weight and waist circumference were measured, maternal and fetal outcomes were recorded and compared in both the groups.

The data was analyzed using chi square test and unpaired t test. A p value $<0.05$ was considered significant.

\section{Results}

The waist circumference in group I varied from $70 \mathrm{~cm}$ to $79 \mathrm{~cm}$ with a mean waist circumference of $76.55 \pm$ $2.002 \mathrm{~cm}$, whereas those in group II had waist circumference ranged from $80 \mathrm{~cm}$ to $115 \mathrm{~cm}$ and the mean was $87.78 \pm 7.230 \mathrm{~cm}$. The age wise distribution of women in two groups is shown in Table 1. The demographic details of both the groups were comparable, maximum women were from urban background (group I-61\%, group II-65\%), educated (group I-85\%, group II-80\%) and unemployed (group I-72\%, group I-64\%). Dietary pattern was also similar in both the groups (group I-76\% vegetarian, 24\% non-vegetarian and group II-67\% vegetarian, 33\% non-vegetarian). Most of the women enrolled for the study were nullipara (68\% in Group I and 65\% in Group II).

Only four women in group I and two in group II had height $\leq 150 \mathrm{~cm}$. Table 2 shows BMI in both the groups. Women with waist circumference $\geq 80 \mathrm{~cm}$ were found to have an increased risk of preeclampsia $(\mathrm{p}=0.0052$, RR 0.5062, 95\% CI 0.2935 - 0.8728), gestational diabetes, macrosomia (birth weight $>4 \mathrm{~kg}$ ) preterm and postdatism as shown in Table 3.

The increased rate of induced labor was observed in group II accounting to 38\% as compared to $21 \%$ in Group I and the difference was statistically very significant (p value 0.0081 , RR 0.6263 , 95\% CI 0.4314 , 0.9091). The rate of failure of induction was also high in group II, $42 \%$, as compared to $19 \%$ in group I and was extremely significant statistically (p value $<0.0001$, RR 0.4588 , 95\% CI 0.1780. 1.182).

The rate of vaginal delivery decreased as the waist circumference increased. There was significantly higher rate of caesarean delivery in women with waist circumference $\geq 80 \mathrm{~cm}(\mathrm{p}=0.0072, \mathrm{RR} 0.5745,95 \%$ CI 0.3696 , 0.8929).

Intrapartum and postpartum complications (Table 4) were significantly different between the groups, 16\% in group I, 35\% in group II ( $\mathrm{p}=0.0033$, RR 0.5565 , 95\% CI $0.3620-0.8554)$.

No significant difference was observed in the mean birth weight among two groups (group I-2.759 $\mathrm{kg} \pm$ 0.4072 , group II $-2.855 \mathrm{~kg} \pm 0.6381, \mathrm{p}=0.2062$ ). In women with waist circumference $\geq 80 \mathrm{~cm}$, $3 \%$ of neonates had very low birth weight, while none of group I weighed less than $1.5 \mathrm{~kg}$. Seventeen percent neonates of group I and $18 \%$ of group II neonates were low birth weight $(<2.5 \mathrm{~kg})$. One percent of group I and $6 \%$ of group II had birth weight $>4 \mathrm{~kg}$.

Perinatal mortality was observed in $2 \%$ of group II women while no perinatal mortality was observed in group I ( $\mathrm{p}=0.4975)$. One percent of group I and $10 \%$ of group II neonates had APGAR score of $<7$ at $5 \mathrm{~min}$,

Table 1. Age wise distribution.

\begin{tabular}{cccc}
\hline \multirow{2}{*}{ Age Interval (Years) } & Group I WC $<\mathbf{8 0} \mathbf{~ c m}$ & Group II WC $\geq \mathbf{8 0} \mathbf{~ c m}$ & p Value \\
\cline { 2 - 4 }$\leq 20$ & $\mathbf{N}=\mathbf{1 0 0}$ & $\mathbf{N}=\mathbf{1 0 0}$ \\
$21-25$ & 4 & 4 \\
$26-30$ & 61 & 53 \\
$31-35$ & 50 & 38 \\
Total & 100 & 5 \\
Mean \pm SD & $24.680 \pm 2.700$ & 100 & \\
\hline
\end{tabular}

WC: Waist circumference. 
Table 2. Body mass index (BMI) wise distribution.

\begin{tabular}{cccc}
\hline BMI $\left(\mathbf{K g} / \mathbf{m}^{-2}\right)$ & $\begin{array}{c}\text { Group I } \\
\text { WC }<\mathbf{8 0} \mathbf{~ c m ~}(\mathbf{n}=\mathbf{1 0 0})\end{array}$ & $\begin{array}{c}\text { Group II } \\
\mathbf{8} \mathbf{~ c m}(\mathbf{n}=\mathbf{1 0 0})\end{array}$ & p Value \\
\cline { 2 - 4 } & Number & Number & \\
\hline $\mathbf{1 8 . 5}-\mathbf{2 4 . 9}$ (Normal) & 95 & 26 & $<0.0001$ \\
$\mathbf{2 5 . 0}-\mathbf{2 9 . 9}$ (Overweight) & 5 & 55 & $<0.0001$ \\
$\mathbf{2 0 . 0}$ (Obese) & 0 & 19 & $<0.0001$ \\
Mean \pm SD & $21.69 \pm 1.628$ & $27.18 \pm 3.656$ & $<0.0001$ \\
\hline
\end{tabular}

Table 3. Antenatal complications among the groups.

\begin{tabular}{cccc}
\hline \multirow{2}{*}{ Antenatal Complication } & $\begin{array}{c}\text { Group I WC }<\mathbf{8 0} \mathbf{~ c m} \\
(\mathbf{n}=\mathbf{1 0 0})\end{array}$ & $\begin{array}{c}\text { Group II WC } \geq \mathbf{8 0} \mathbf{~ c m} \\
(\mathbf{n}=\mathbf{1 0 0})\end{array}$ & p Value \\
\cline { 2 - 4 } No of Women & No of Women & \\
\hline Preeclampsia & 10 & 26 & 0.0052 \\
Gestational Diabetes Mellitus & 2 & 6 & 0.2790 \\
Macrosomia & 1 & 6 & 0.1184 \\
$<\mathbf{3 7}$ (preterm) & 10 & 12 & 0.8217 \\
-Spontaneous Preterm Birth & 7 & 5 & 0.2305 \\
-Indicated Preterm Birth & 3 & 7 & 0.2305 \\
$>\mathbf{4 0}$ (Postdated) & 6 & 16 & 0.0400 \\
\hline
\end{tabular}

Table 4. Intrapartum and postpartum complications.

\begin{tabular}{cccc}
\hline \multirow{2}{*}{ Complications } & $\begin{array}{c}\text { Group I } \\
\text { WC }<\mathbf{8 0 ~} \mathbf{~ c m}(\mathbf{n}=\mathbf{1 0 0})\end{array}$ & $\begin{array}{c}\text { Group II } \\
\text { WC } \mathbf{8 0 ~} \mathbf{~ c m}(\mathbf{n}=\mathbf{1 0 0})\end{array}$ & p Value \\
\cline { 2 - 3 } Fetal Distress & Number & Number & 0.5647 \\
Shoulder Dystocia & 6 & 12 & 0.2425 \\
3 Perineal Tear & 2 & 5 & 0.3234 \\
Postpartum Hemorrhage & 1 & 9 & 1.0000 \\
Wound Infection & 4 & 6 & 1.0000 \\
Total & 3 & 35 & 0.0033 \\
\hline
\end{tabular}

the difference was statistically found to be very significant ( $p=0.0097)$. Neonatal admission to neonatal intensive care unit was $10 \%$ in group I as compared to $18 \%$ of group II neonates and was not significant $(p=0.1528)$.

At 6 week follow up visit, 28 women in group I and 16 in group II lost to follow up after discharge. Out of those who came for follow up at 6 weeks, none among the group I had high blood pressure or raised plasma glucose levels, and among the group II women, 1 (1.19\%) had high blood pressure and none had raised plasma glucose levels.

\section{Discussion}

Obesity is a condition characterized by excess of body fat, frequently resulting in impairment of health and longevity. It is usually assessed clinically by body mass index. The ideal time to record the baseline weight for calculation of BMI of a pregnant women is before she has started gaining weight due to gestation, which is seldom available. Studies have shown that abdominal adiposity has adverse effects on health, regardless of BMI. Abdominal adiposity, measured by waist circumference, is a good marker of fat distribution, can be easily self 
measured and has been considered as a better indicator of obesity related health risks than BMI [12].

Women in age group 18 - 35 years were enrolled for the study, the mean age was similar to that of Wendland et al. [13] (27.6 \pm 5.3 years). The demographic profile of women was similar in the two groups as women in both the groups were coming from similar background and were enrolled at a tertiary care centre. In the present study, most of the women were nullipara, thus indicating that the nulliparas reported for antenatal visit earlier in the pregnancy.

We measured waist circumference of all women at booking visit before 8 weeks of gestation as at this time pregnancy will not affect the waist circumference and is in accordance with the study of Sattar et al. [12]. The cut off value of $80 \mathrm{~cm}$ was taken based on Asian population. There is higher percentage of body fat in Asians at lower BMI. So, lower threshold is needed for indicating the increased risk in this ethnicity.

Among the group II, we had not taken $>88 \mathrm{~cm}$ as separate group as there were only a few women with waist circumference $>88 \mathrm{~cm}$.

In women with waist circumference $\geq 80 \mathrm{~cm}, 26 \%$ had normal BMI $\left(18.5-24.9 \mathrm{~kg} / \mathrm{m}^{-2}\right)$ thereby indicating that a normal BMI does not necessarily indicate normal levels of abdominal obesity. The height $<150 \mathrm{~cm}$ was found in a few women in both the groups, this suggests that height had no influence on waist circumference as the bony landmark was taken into consideration for measuring waist circumference.

Women with waist circumference $\geq 80 \mathrm{~cm}$ had increased risk of complications, in the present study, Few studies have reported the role of waist circumference in predicting preeclampsia, gestational Diabetes Mellitus, macrosomia. Preeclampsia was the major contributor to the maternal and perinatal morbidity. Preeclampsia developed in $26 \%$ of group II women as compared to $10 \%$ of group I women which corresponds to that of other studies [12]-[14].

In the present study, gestational diabetes mellitus was diagnosed in $6 \%$ of women with waist circumference $\geq$ $80 \mathrm{~cm}$. The study of Wendland et al. [13] reported gestational diabetes in 5.5\%, 7.9\% and 13.5\% in women with $83 \mathrm{~cm}, 88 \mathrm{~cm}$ and $122 \mathrm{~cm}$ waist circumference quintiles, which was found to be comparable with the present study. Brisson et al. [15] reported glycemia on a two hour glucose tolerance test in $18.0 \%$ women with waist circumference $>85 \mathrm{~cm}$.

Macrosomia was reported higher in group II (6\%) as compared to group I (1\%) women in the present study consistent with other studies [13] [16] [17]. Wendland et al. [13] in their study identified macrosomia in 9\%, $11.4 \%$ and $17.1 \%$ in women having $83 \mathrm{~cm}, 88 \mathrm{~cm}$ and $112 \mathrm{~cm}$ waist circumference quintiles. A study conducted by Usha Kiran et al. [16] comparing obese and non-obese based on BMI reported macrosomia in 14.8\% of obese and $7.6 \%$ of non-obese women. Out of the 6 macrosomic neonates in group II, 3 were associated with gestational diabetes mellitus and the rest 3 were seen in women with very high waist circumference $(>88 \mathrm{~cm})$.

Both the preterm and postdated deliveries were higher in group II. The indicated preterm births were higher in group II (58.4\%) as compared to group I (30\%), while the spontaneous preterm births were lower in comparison to group I. These findings were consistent with the study by Hendler et al. [18], Cnattingius et al. [19]. Bhattacharya et al. [11] in their study found that obese women were at increased risk of delivery before 33 weeks (OR 2.0, 95\% CI 1.3, 2.9), but the rate of postdated delivery was similar. More women in group II, required induction of labour and in agreement with other studies [11] [16] [17].

The present study observed that the rate of caesarean delivery was more in the women with waist circumference $\geq 80 \mathrm{~cm}$ and this was found in concordance with that of Verma and Shrimaili, ${ }^{3}$ Addo VN ${ }^{17}$, Burstein et al. [20] (32.9\% in obese, 9\% in non-obese), Usha Kiran et al. [16] (27\% of obese women, 18\% of non-obese women). Out of the vaginal births, $4.7 \%$ in group I and $11.5 \%$ in group II required instrumentation with either forceps or vacuum in the present study and was statistically insignificant.

Intrapartum and postpartum complications was found to be more in women with waist circumference $\geq 80 \mathrm{~cm}$. There was no significant difference on comparing each complication in both groups as the number is small but significant difference was noted in overall complications. It was observed that the excessive blood loss in group II women was associated not only with caesarean delivery but also with vaginal delivery. Usha Kiran et al. [16] on comparing non-obese and obese, based on BMI, reported increased risk of shoulder dystocia $(0.5 \%$ in non-obese vs. $1.5 \%$ in obese), third and fourth degree perineal tear ( $0.7 \%$ on non-obese vs. $0.8 \%$ in obese), post partum hemorrhage (15.5\% in non-obese vs. $22 \%$ in obese) and wound infection (1.7\% in non-obese vs. $1.6 \%$ in obese) in obese women. Sebire et al. [7] also reported an increased risk of postpartum hemorrhage in obese women.

Implications of obesity in pregnant woman for the infant included sub-optimal gestational age (both preterm 
and postdate), stillbirth, low- and high-birth weight, fetal distress and neonatal intensive care. Usha Kiran et al. [16] reported $<7$ APGAR score at 5 min in $0.9 \%$ neonates of non-obese women and in $1.2 \%$ neonates of obese women. Bhattacharya et al. [11] also reported higher stillbirth rates in the obese (1.9\%) as compared to normal BMI categories $(0.9 \%)$.

In the present study, $18 \%$ of group II neonates were admitted to NICU as compared to $10 \%$ in Group I and shifted to mother side later. Usha Kiran et al. [16] also reported increased NICU admissions in obese group (3.8\%) compared to $2.5 \%$ in non-obese group.

To, our knowledge, this is the first prospective study to correlate the waist circumference with the maternal and neonatal outcome. The limitations of our study are the moderate sample size as it did not allow subgroups and follow up in a single centre.

\section{Conclusion}

This clinically defined waist circumference threshold $(80 \mathrm{~cm})$ for abdominal obesity has been found to be associated with various maternal and neonatal complications. Even women with normal BMI had increased waist circumference and related to high risk of pregnancy complications. Waist circumference can be used to assess the pregnancy risks associated with overweight and obesity. Assessment of waist circumference in early pregnancy (before 8 weeks) provides a simple and practical anthropometric parameter for predicting pregnancy related adverse outcomes. It is suggested that all pregnancies in centrally obese women shall be acknowledged as high risk. Preconception counseling and interventions to reduce weight should be targeted at women who have waist circumference $\geq 80 \mathrm{~cm}$.

\section{Conflict of Interests}

The authors declare that they have no conflict of interest.

\section{References}

[1] World Health Organization (2012) Obesity and Overweight. Report of a WHO Consultation. Fact sheet No 311, World Health Organisation, Geneva.

[2] Verma, A. and Shrimali, L. (2012) Maternal Body Mass Index and Pregnancy Outcome. Journal of Clinical and Diagnostic Research, 6, 1531-1533. http://dx.doi.org/10.7860/jcdr/2012/4508.2551

[3] National Institute of Health and Clinical Excellance (2006) Obesity: Guidance on the Prevention, Identification, Assessment and Management of Overweight and Obesity in Adults and Children. Clinical Guideline, 43.

[4] Pouliot, M.C., Despres, J.P., Lemieux, S., Moorjani, S., Bouchard, C., Tremblay, A., et al. (1994) Waist Circumference and Abdominal Sagittal Diameter: Best Simple Anthropometric Indices of Abdominal Visceral Adipose Tissue Accumulation and Related Cardiovascular Risk in Men and Women. American Journal of Cardiology, 73, 460-468. http://dx.doi.org/10.1016/0002-9149(94)90676-9

[5] Heslehurst, N., Ells, L.J., Simpson, H., Batterham, A., Wilkinson, J. and Summerbell, C.D. (2007) Trends in Maternal Obesity Incidence Rates, Demographic Predictors, and Health Inequalities in 36,821 Women over a 15-Year Period. BJOG, 114, 187-194. http://dx.doi.org/10.1111/j.1471-0528.2006.01180.x

[6] Sebire, N.J., Jolly, M., Harris, J.P., Wadsworth, J., Joffe, M., Beard, R.W., et al. (2001) Maternal Obesity and Pregnancy Outcome: A Study of 287,213 Pregnancies in London. International Journal of Obesity, 25, 1175-1182. http://dx.doi.org/10.1038/sj.ijo.0801670

[7] Oken, E., Rifas-Shiman, S.L., Field, A.E., Frazier, A.L. and Gillman, M.W. (2008) Maternal Gestational Weight Gain and Offspring Weight in Adolescence. Obstetrics \& Gynecology, 112, 999-1006. http://dx.doi.org/10.1097/AOG.0b013e31818a5d50

[8] Boney, C.M., Verma, A., Tucker, R. and Vohr, B.R. (2005) Metabolic Syndrome in Childhood: Association with Birth Weight, Maternal Obesity, and Gestational Diabetes Mellitus. Pediatrics, 115, e290-296. http://dx.doi.org/10.1542/peds.2004-1808

[9] Vasudevan, C., Renfrew, M. and McGurie, W. (2011) Fetal and Perinatal Consequences of Maternal Obesity. Arch Dis Child Fetal Neonatal Ed., 96, F378-F382. http://dx.doi.org/10.1136/adc.2009.170928

[10] Bhattacharya, S., Campbell, D.M., Liston, W.A. and Bhattacharya, S. (2007) Effect of Body Mass Index on Pregnancy Outcomes in Nulliparous Women Delivering Singleton Babies. BMC Public Health, 7, 168.

http://dx.doi.org/10.1186/1471-2458-7-168 
[11] National Institute of Health and Clinical Excellence (2006) Obesity: Guidance on the Prevention, Identification, Assessment and Management of Overweight and Obesity in Adults and Children. NICE Clinical Guidelines No. 43.

[12] Satter, N., Clark, P., Holmes, A., Lean, M.E.J., Walker, I. and Greer, I. (2001) Antenatal Waist Circumference and Hypertension Risk. Obstetrics \& Gynecology, 97, 268-271. http://dx.doi.org/10.1016/S0029-7844(00)01136-4

[13] Wendland, E.M.D.R., Duncan, B.B., Mengue, S.S., Nucci, L.B. and Schmidt, M.I. (2007) Waist Circumference in the Prediction of Obesity-Related Adverse Pregnancy Outcomes. Cadernos de Saúde Pública, 23, 391-398. http://dx.doi.org/10.1590/S0102-311X2007000200015

[14] Briese, V., Voigt, M., Wisser, J., Borchardt, U. and Straube, S. (2011) Risks of Pregnancy and Birth in Obese Primiparous Women: An Analysis of German Perinatal Statistics. Archives of Gynecology and Obstetrics, 283, $249-253$. http://dx.doi.org/10.1007/s00404-009-1349-9

[15] Brisson, D., Perron, P., Guay, S.P., Gaudet, D. and Bouchard, L. (2010) The "Hypertriglyceridemic Waist” Phenotype and Glucose Intolerance in Pregnancy. Canadian Medical Association Journal, 182, E722-E725. http://dx.doi.org/10.1503/cmaj.100378

[16] Usha Kiran, T.S., Hemmadi, S., Bethel, J. and Evans, J. (2005) Outcome of Pregnancy in a Woman with an Increased Body Mass Index. BJOG: An International Journal of Obstetrics and Gynaecology, 112, 768-772. http://dx.doi.org/10.1111/j.1471-0528.2004.00546.x

[17] Addo, V.N. (2010) Body Mass Index, Weight Gain during Pregnancy and Obstetric Outcomes. Ghana Medical Journal, 44, 64-69.

[18] Hendler, I., Goldenberg, R.L., Mercer, B.M., Iams, J.D., Meis, P.J., Moawad, A.H., et al. (2005) The Preterm Prediction Study: Association between Maternal Body Mass Index and Spontaneous and Indicted Preterm Birth. American Journal of Obstetrics \& Gynecology, 192, 882-886. http://dx.doi.org/10.1016/j.ajog.2004.09.021

[19] Cnattingius, S., Villamor, E., Johansson, S., Bonamy, A.E., Persoson, M., Wikstrom, A., et al. (2013) Maternal Obesity and Risk of Preterm Delivery. Journal of the American Medical Association, 309, 2362-2370. http://dx.doi.org/10.1001/jama.2013.6295

[20] Burstein, E., Levy, A., Mazor, M., Witznitzer, A. and Sheiner, E. (2008) Pregnancy Outcome among Obese Women: A Prospective Study. American Journal of Perinatology, 25, 561-566. http://dx.doi.org/10.1055/s-0028-1085623 